\title{
Comparative analysis of excretory-secretory antigens of Trichinella spiralis and Trichinella britovi muscle larvae by two-dimensional difference gel electrophoresis and immunoblotting
}

Justyna Bien ${ }^{1 *}$, Anu Näreaho², Pekka Varmanen³, Katarzyna Gozdzik', Bozena Moskwa', Wladyslaw Cabaj', Tuula A Nyman ${ }^{4}$ and Kirsi Savijoki ${ }^{3,4}$

\begin{abstract}
Background: Trichinellosis is a zoonotic disease in humans caused by Trichinella spp. The present study was undertaken to discover excretory-secretory (E-S) proteins from T. spiralis and T. britovi muscle larvae (ML) that hold promise for species-specific diagnostics. To that end, the purified E-S proteins were analyzed by fluorescent twodimensional difference gel electrophoresis (2-D DIGE) coupled with protein identification by liquid chromatography-tandem mass spectrometry (LC-MS/MS). To search for immunoreactive proteins that are specifically recognized by host antibodies the E-S proteins were subjected to two-dimensional (2-DE) immunoblotting with antisera derived from pigs experimentally infected with $T$. spiralis or T. britovi.

Results: According to 2-D DIGE analysis, a total of twenty-two proteins including potentially immunogenic proteins and proteins produced only by one of the two Trichinella species were subjected to LC-MS/MS for protein identification. From these proteins seventeen could be identified, of which many were identified in multiple spots, suggesting that they have undergone post-translational modification, possibly involving glycosylation and/or proteolysis. These proteins included 5'-nucleotidase, serine-type protease/proteinase, and p43 glycoprotein (gp43) as well as $49 \mathrm{kDa}$ E-S protein (p49). Our findings also suggest that some of the commonly identified proteins were post-translationally modified to different extents, which in certain cases seemed to result in species-specific modification. Both commonly and specifically recognized immunoreactive proteins were identified by 2-DE immunoblotting; shared antigens were identified as gp43 and different protease variants, whereas those specific to T. britovi included multiple isoforms of the 5 '-nucleotidase.
\end{abstract}

Conclusions: Both 2-D DIGE and 2-DE immunoblotting approaches indicate that T. spiralis and T. britovi produce somewhat distinctive antigen profiles, which contain E-S antigens with potential as species-specific diagnostic markers for Trichinella. Our results also demonstrate the value of 2-D DIGE as a versatile tool to compare secretomes of different Trichinella species for pinpointing factors contributing to the interaction with the host.

Keywords: 2-D DIGE, E-S, Trichinella spiralis, Trichinella britovi, Immunoblotting

\footnotetext{
* Correspondence: jbien@twarda.pan.pl

'Witold Stefanski Institute of Parasitology of the Polish Academy of Sciences,

51/55 Twarda Street, 00818 Warsaw, Poland

Full list of author information is available at the end of the article
} 


\section{Background}

Trichinellosis is a food-borne parasitic zoonosis caused by nematodes of the genus Trichinella. Twelve genotypes of Trichinella have been identified worldwide [1-3], four of which are confirmed to exist in Europe: $T$. spiralis, T. nativa, T. britovi and T. pseudospiralis. In Poland, during various epidemiological surveys, only two Trichinella species have been identified in domestic and wild animals, T. spiralis and T. britovi $[4,5]$. T. spiralis is the etiological agent of most human infections and deaths caused by trichinellosis globally, although other encapsulating and nonencapsulating species can cause human infections, including T. britovi, T. nativa, and $T$. pseudospiralis [6-11]. Trichinellosis is mainly acquired by the ingestion of domestic animal meat, such as pig and horse meat, that contains infective larvae. In addition to domestic sources of infection, sylvatic transmission via the consumption of wild game is also an important source of human infection $[6,7,12]$. Mixed Trichinella species infections appear to be a common phenomenon, and have been reported in several host species [13-18].

The life-cycle of Trichinella spp. begins with the consumption of meat that contains infective muscle larvae (ML). In the host stomach, larvae are released into gastric fluid and develop into adult worms (females and males) in the host intestine, and the female begins to release the newborn larvae (NBL). The NBL penetrate the intestinal wall, enter the lymphatic system, and migrate through the bloodstream into striated muscle where it infects and encapsulates within a portion of the myofiber and develops into the infective muscle larvae. During this process an intimate host-parasite interaction is formed [19]. Trichinella spp. are believed to modulate host cell functions for their own benefit, and in this process the excretory-secretory (E-S) proteins produced by muscle larvae are believed to play a crucial role [20].

Although clinical differences have been observed among people infected with different species of Trichinella, it has not been possible to attribute these differences to the species of the pathogen because the number of infecting larvae ingested by each person was generally unknown [21]. The clinical and biological features observed during human infection with T. spiralis appear to have been different from those caused due to T. britovi. The main distinctions between the two types of infections were a longer duration of parasite-specific IgG, increased creatine phosphokinase (CPK) levels, and a more severe intestinal symptomatology in T. spiralisinfected patients than in those infected with $T$. britovi, and this could be due to the fact that $T$. britovi females are less profilic [22]. T. murrelli seems to be more likely to provoke skin reactions and facial oedema [23]. T. pseudospiralis, which is non-encapsulated, seems to provoke signs and symptoms that last longer [24,25].

Up to now, it has not been possible to differentiate Trichinella species serologically, although several methods including ELISA, Western Blot, immunochemical and immunoprecipitation assays are widely used for the diagnosis of Trichinella in humans [21,26-30]. Serological methods are not particularly appropriate for early and species-specific diagnostics. Nevertheless, diagnostics could be greatly improved if the infecting species can be identified serologically. Therefore, information about E-S antigens, that are common or unique to different Trichinella species, is required to aid the development of species-specific diagnostics. A genome sequence, enabling all potential E-S antigens in T. spiralis to be pinpointed, was recently completed [31]. Nonetheless, as the genetic information is only indicative of the cell's potential, proteome-wide analysis is needed to complement the genetic information.

Fluorescent two-dimensional difference gel electrophoresis (2-D DIGE) is the latest multiplexed innovation in two-dimensional gel electrophoresis (2-DE), which incorporates distinctive fluorescent dyes, and enables detection of relative protein abundance differences with over a 10,000-fold protein concentration range [32-34]. Protein analysis based on 2-DE is also the method of choice to demonstrate post-translational modifications involving, for example, glycosylation, phosporylation or proteolysis. The proteomic studies reported for Trichinella were based on the application of the classical 2-DE and have been highly effective in the characterization of the proteomes of different species of Trichinella, including T. spiralis, T. britovi, T. pseudospiralis, T. nativa and T8 [35-39].

In the current study we applied 2-D DIGE technique and 2-DE immunoblotting to uncover common and unique E-S proteins produced by $T$. spiralis and $T$. britovi muscle larvae.

\section{Methods \\ Parasites}

Trichinella spiralis (strain ISS-003) and T. britovi (strain ISS-002) ML (Istituto Superiore di Sanita, The International Trichinella Reference Centre) were maintained in female Balb/c mice. ML of both species were isolated from infected mice as previously described $[40,41]$.

\section{Collection and preparation of E-S proteins}

Larvae of T. spiralis and T. britovi were washed several times in pre-warmed RPMI 1640 medium (SigmaAldrich Chemie $\mathrm{GmbH}$, Steinheim) and resuspended at 5000 larvae $\mathrm{ml}^{-1}$ in RPMI containing $2 \mathrm{mM}$ L-glutamine, and antibiotics $\left(100 \mathrm{U} \mathrm{ml}^{-1}\right.$ penicillin, $100 \mu \mathrm{g} \mathrm{ml}^{-1}$ 
streptomycin). $\mathrm{ML}$ were incubated with $5 \% \mathrm{CO}_{2}$ in a 75 $\mathrm{cm}^{2}$ culture flask at $37^{\circ} \mathrm{C}$ for up to $18 \mathrm{~h}$, after which they were allowed to sediment by settling in $50 \mathrm{ml}$ conical tubes. The culture supernatants containing the E-S proteins were filtered through a $0.22 \mu \mathrm{m}$ filter and then concentrated by lyophilization.

\section{CyDye labeling of E-S proteins}

The E-S extracts of T. spiralis and T. britovi were purified using a 2-D Clean-Up Kit (GE Healthcare) and solubilised in 10-20 $\mu \mathrm{L}$ of UTCT composed of $7 \mathrm{M}$ urea (Sigma-Aldrich), $2 \mathrm{M}$ thiourea (Sigma-Aldrich), 4\% CHAPS (Sigma-Aldrich) and $30 \mathrm{mM}$ Trizma base (BioRad). The protein concentration was determined using a 2-D Quant Kit (GE Healthcare) according to the manufacturer's protocol. Prior to CyDye labelling, the $\mathrm{pH}$ of each protein sample was adjusted to 8.5 by the addition of UTCT. Both the T. spiralis and T. britovi protein samples were divided in four to represent technical replicate samples prior to CyDye labelling. The samples were then labelled using $\mathrm{Cy} 2, \mathrm{Cy} 3$, or Cy5 dyes (CyDye DIGE Fluor minimal dyes; GE Healthcare), according to the Ettan ${ }^{\mathrm{TM}}$ 2-D DIGE protocol. Briefly, approximately $12.5 \mu \mathrm{g}$ of protein from $T$. spiralis and T. britovi was labelled with $200 \mathrm{pmol}$ of the Cy3 and Cy5 dyes. As an internal standard, aliquots from each sample were combined and labelled with $\mathrm{Cy} 2$ dye. To exclude dye-specific effects, Cy3 and Cy5 were used interchangeably according to a dye-swapping approach (Table 1). The labelling mixtures were incubated on ice in the dark for $30 \mathrm{~min}$ and the reactions were quenched with $1 \mathrm{mM}$ lysine (Sigma-Aldrich) followed by incubation on ice for 10 min. The labelled samples were pooled and separated by 2-DE as detailed below.

\section{2-DE and DeCyder analysis}

CyDye labeled protein samples were separated by isoelectric focusing (IEF) using IPG strips $(11 \mathrm{~cm}, \mathrm{NL}, \mathrm{pH}$ 3-10, Bio-Rad) and a Protean IEF Cell (Bio-Rad). The IEF strips were rehydrated overnight in $500 \mu \mathrm{L}$ of the rehydration solution (GE Healthcare) containing $1 \%$ Bio-Lyte pH 3-10 (Bio-Rad). Samples containing

Table 1 Setup of a DIGE experiment using four technical repeats of E-S protein samples and a dye swap between Cy3 and Cy5

\begin{tabular}{llll}
\hline Gel number & Cy3 & Cy5 & Cy2 \\
\hline 1 & TS1 $^{\mathrm{a}}$ & $\mathrm{TB1}^{\mathrm{a}}$ & Mix $^{\mathrm{b}}$ \\
2 & $\mathrm{TS} 2$ & TB2 & Mix \\
3 & TB3 & TS3 & Mix \\
4 & TB4 & TS4 & Mix \\
\hline
\end{tabular}

${ }^{\mathrm{a}} \mathrm{TS}$ and TB refers to E-S protein samples concentrated and purified from $T$. spiralis and $T$. britovi, respectively

${ }^{\mathrm{b}}$ Mix refer mixture of samples of all four repeats approximately $50 \mu \mathrm{g}$ protein in $5 \mathrm{mM}$ DTT, $5 \mathrm{mM}$ tributylphosphine, and 1\% Bio-Lyte pH 3-10 were applied to the IPG strips by cup-loading. IEF was performed using a Protean IEF Cell at $20^{\circ} \mathrm{C}$ as follows: $15 \mathrm{~min}$ at $250 \mathrm{~V}$, then linear ramping to $8000 \mathrm{~V}$ for $25,000 \mathrm{Vh}$, and $8000 \mathrm{~V}$ for $10,000 \mathrm{Vh}$ (using a limit of $50 \mu \mathrm{A} /$ strip).

After IEF the strips were first equilibrated for $25 \mathrm{~min}$ in a buffer containing $50 \mathrm{mM}$ Tris- $\mathrm{HCl}(\mathrm{pH} 6.8), 6 \mathrm{M}$ urea, $2 \%$ SDS, and $20 \%$ glycerol and supplemented with 2\% DTT (buffer A), followed by a 25 min equilibration in the same buffer in which DTT was replaced with $2.5 \%$ iodoacetamide (buffer B). The second dimension SDS-PAGE was run on Criterion PreCast gels $(12.5 \%$ Tris- $\mathrm{HCl}$ gels, BioRad) in a Criterion Dodeca Cell (BioRad) with $200 \mathrm{~V}$ for approximately one hour.

The gels were scanned between low fluorescence glass plates using a FLA-5100 laser scanner (Fujifilm) at wavelengths of $473 \mathrm{~nm}$ (for Cy2), $532 \mathrm{~nm}$ (Cy3), and $635 \mathrm{~nm}$ (Cy5) using voltages of 420, 410, and $400 \mathrm{~V}$, accordingly (with $100 \mu \mathrm{m}$ resolution). The gel images were cropped to identical size by removing areas extraneous to the protein spots with ImageQuant TL 7.0 software (GE Healthcare). After scanning, the gels were fixed in $30 \%$ ethanol and $0.5 \%$ acetic acid for $60 \mathrm{~min}$ minimum and then silver stained [42]. Image and statistical analyses for the cropped 2-D DIGE gels were performed using DeCyder 2D 6.5 software (GE Healthcare). With the use of a batch processor function, the gels were first automatically analysed in a differential in-gel analysis (DIA) module, which normalized the Cy2, Cy3, and Cy5 image from each gel. Spot boundaries were detected, and spot volumes (protein abundances) were calculated. Then, the spot volumes of Cy3 and Cy5 samples were compared with the spot volumes of the $\mathrm{Cy} 2$ sample (internal standard) to generate standard spot volumes, thereby correcting intergel variations. In the biological variation analysis (BVA) module, the Cy2 images of four replicate gels were matched, and the standard spot volume ratios between all four gels were compared. The DeCyder BVA module was used to matching multiple 2-D DIGE gels for comparison and statistical analysis of protein abundance changes. Spots with at least a 1.2-fold spot volume ratio change and a $p$ value of lower than 0.05 were selected for identification.

\section{LC-MS/MS analysis}

Mass spectrometric (MS)-compatible silver staining [43] was performed to visualize the protein spots for identification. Protein spots of interest were in-gel digested with trypsin and the peptides recovered as previously described [44]. The resulting peptides were analyzed by fragment ion analysis with LC-MS/MS using an Ultimate 3000 nano-LC (Dionex, Sunnyvale, CA, USA) and QSTAR Elite hybrid quadrupole TOF mass 
spectrometer (Applied Biosystems/MDS Sciex, Foster City, CA, USA) with nano-ESI ionisation. The samples were first concentrated and desalted on a $\mathrm{C}_{18}$ trap column $\left(10 \mathrm{~mm} \times 150 \mu \mathrm{m}, 3 \mu \mathrm{m}, 120 \AA\right.$ A , PROTECOL ${ }^{\mathrm{TM}}$; SGE Analytical Science, Griesheim, Germany) followed by peptide separation on a PepMap $100 \mathrm{C}_{18}$ analytical column $(15 \mathrm{~cm} \times 75 \mu \mathrm{m}, 5 \mu \mathrm{m}, 100 \AA$; LC Packings, Sunnyvale, CA, USA) at $200 \mathrm{nl} / \mathrm{min}$. The separation gradient consisted of $0-50 \% \mathrm{~B}$ in $20 \mathrm{~min}, 50 \% \mathrm{~B}$ for $3 \mathrm{~min}$, $50-100 \%$ B in 2 min and $100 \%$ B for 3 min (buffer A: $0.1 \%$ formic acid; buffer B: $0.08 \%$ formic acid in $80 \%$ acetonitrile). MS data were acquired using Analyst QS 2.0 software. Information-dependent acquisition method consisted of a $0.5 \mathrm{~s}$ TOF-MS survey scan of $\mathrm{m} / \mathrm{z} 400-$ 1400. From every survey scan two most abundant ions with charge states +2 to +4 were selected for product ion scans. Once an ion was selected for MS/MS fragmentation, it was put on an exclusion list for $60 \mathrm{~s}$.

\section{Protein identification}

All LC-MS/MS results were analyzed using the ProteinPilot ${ }^{\mathrm{TM}}$ (version 2.0.1, Applied Biosystems) software. The MS/MS data were searched against the NCBINr database 20111206 (16392747 sequences; 5641810382 residues) restricted to Metazoa (Metazoa (Animals) (2796749 sequences) and/or Other Metazoa (989730 sequences) using Mascot (Matrix Science, version 2.2.03). The search criteria for were: trypsin digestion with one missed cleavage allowed, carbamidomethyl modification of cysteine as a fixed modification and oxidation of methionine as variable modification. For the LC-MS/MS spectra both the maximum precursor ion mass tolerance and MS/MS fragment ion mass tolerance were $0.2 \mathrm{Da}$, and peptide charge state of $+1,+2,+3$ was used. A successful identification was reported when a significant match $(p<$ $0.05)$ was obtained.

\section{2-DE coupled with immunoblotting}

For two-dimensional immunoblotting, rehydration of IPG strips (13 cm, NL, pH 3-10), IEF followed by 2-DE separation of T. spiralis and T. britovi E-S proteins (50 $\mu \mathrm{g}$ each) was performed as described above. After 2-DE, proteins were transferred to a polyvinylidene fluoride membrane (Bio-Rad) that was then exposed to sera from experimentally $T$. spiralis or T. britovi infected pigs (1:100), followed by goat anti-pig IgG conjugated to horse-radish peroxidase (1:20 000; Bethyl Laboratories. Inc). The blots were developed using the SuperSignal West Dura Extended Duration kit (Pierce) and visualized with a Fuji LAS3000 CCD camera (Fuji Photo Co. Ltd, Japan). The experiment was performed using two biological replicate samples.

\section{Results and Discussion}

\section{D DIGE analysis of $T$. spiralis and $T$. britovi proteomes}

The present study aimed to identify antigenic E-S proteins produced by $T$. spiralis and T. britovi which may elicit an immune response in infected pigs, and thus hold promise as potential target proteins for species-specific diagnostics. To meet this goal, we have previously conducted immunoblot analyses to estimate the size of the T. spiralis and T. britovi E-S proteins that crossreact with species-specific antisera (data not shown). To gain more knowledge of these proteins and to pinpoint which antigens are uniquely produced we wished to apply 2D DIGE that enables quantative comparison of the indicated E-S proteins in the same gel. For this purpose, four technical replicate samples (each containing $12.5 \mu$ g protein) were differentially labeled with CyDye labels and pooled for IEF and 2D separation using the experimental setup in Table 1. Co-detection of the scanned 2D gel images using DeCyder software enabled detection of 150-200 spot features in both Trichinella proteomes over the $\mathrm{pI}$ range of 3-10. Figures $1 \mathrm{~A}, \mathrm{~B}$ and $2 \mathrm{~A}$ show the fluorescent and the typical $\mathrm{Cy} 5 / \mathrm{Cy} 3$ overlays of the T. spiralis and T. britovi specific E-S proteomes. The T. spiralis and T. britovi E-S proteomes are distinctly different (Figure 2A). After BVA analysis each proteome was shown to contain 44 proteins exhibiting differential abundance ( $>1.2$-fold spot volume ratio change and $p<0.05$ ) or appearing only in one of the two proteomes. From these protein spots fourteen (spots 4, 6, 18, 20, 28, 32, 34, 35, 40, 41, 43, 50, 51 and 65 ) were found to be specifically produced by $T$. spiralis, whereas only eight proteins were uniquely produced by T. britovi (spots 2, 9, 19, 22, 24, 42, 57 and 60) (Figure $1 \mathrm{~A}, \mathrm{~B}, 2 \mathrm{~A})$. A three-dimensional view of the 2-DE gel regions containing chosen species-specific protein spots further support the unique appearance of the proteins in T. spiralis and T. britovi E-S proteomes (Figure 3A, B). The remainder of the protein spots (22 in total), were expected to contain proteins that are produced in different amounts by $T$. spiralis and T. britovi, as evidenced for the selected protein spots in Figure 3A, B.

\section{Majority of the proteins were identified as having multiple charge isoforms}

We have previously observed that the potentially immunogenic E-S proteins could migrate with $\mathrm{Mw}$ values between 30 and $50 \mathrm{kDa}$ (data not shown). Thus, from all $T$. spiralis and T. britovi proteins showing different abundance we selected protein spots that migrate within this region for identification by LC-MS/MS. We also selected a subset of other proteins that seemed to be uniquely produced by either one of the two species to gain deeper insight into the mechanisms by which these 

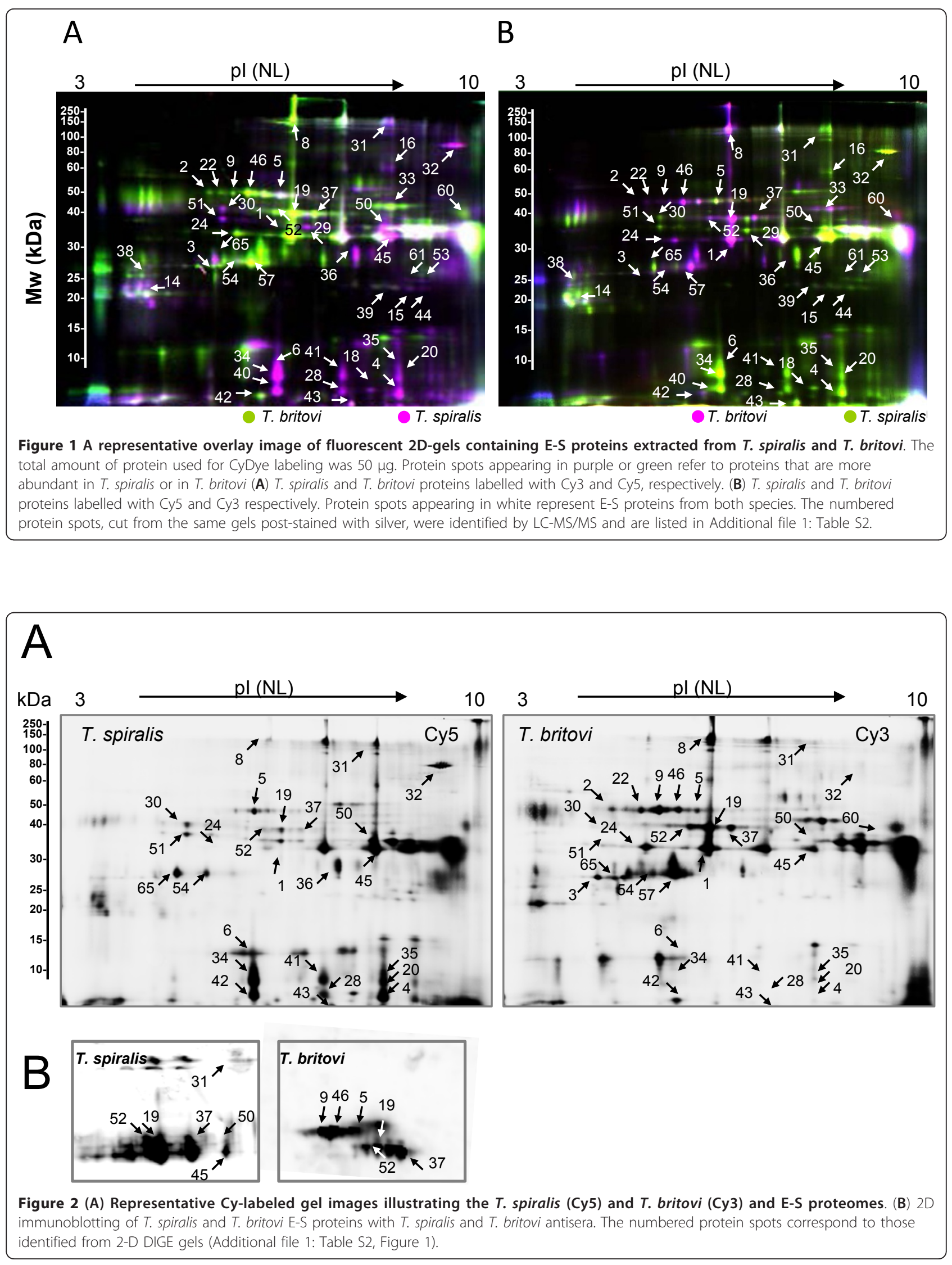


\section{A \\ B}

Proteins more abundant or unique in $T$. spiralis
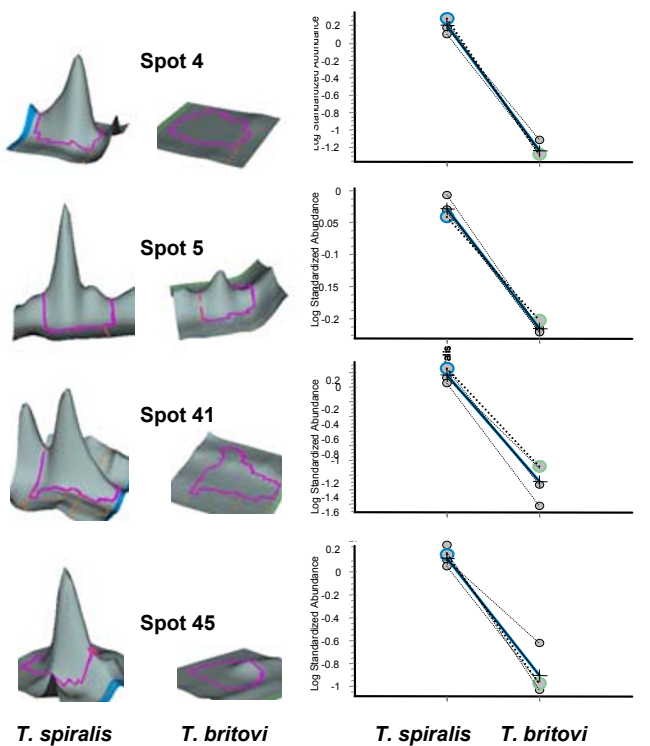

T. britovi

T. spiralis T. britovi

Proteins more abundant or unique in $T$. britovi
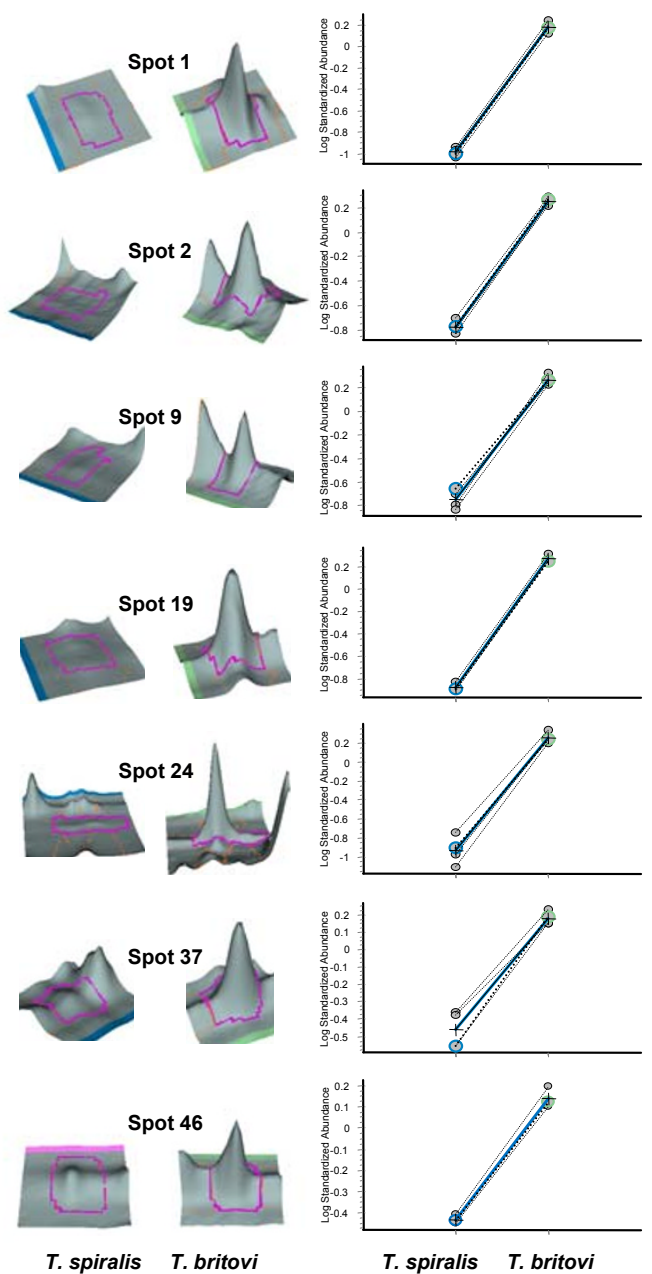

Figure 3 A representative three-dimensional (3D) image of chosen DIGE spots that are more abundant or unique in $T$. spiralis (A) or $T$. britovi (B) 3D images and statistics were generated using the BVA module of the DeCyder software

two different species infect the host. Thus, in total of twenty-two protein spots were selected for final identification, and from these spots only seventeen proteins were successfully identified (Additional file 1: Table S2). In the $T$. spiralis E-S proteome, the specifically appearing protein spots were identified as a probable 5'nucleotidase, a glycoprotein p43 (gp43) and two potential serine proteases with different $\mathrm{pI}$ and molecular weight values (Additional file 1: Table S2, Figure 1A, B). The species-specific protein spots appearing only in the $T$. britovi E-S proteome were also found to contain a potential 5'nucleotidase, serine protease/proteinase and $49 \mathrm{kDa}$ E-S antigen (p49), which all were identified in multiple protein spots (Additional file 1: Table S2; Figure $1 \mathrm{~A}, \mathrm{~B})$. There are a number of possible explanations for these different isoforms, including amino acid sequence differences, alternative splicing, or post-translational modifications. Similarly, Robinson and Connolly [36] identified 43 out of $52 \mathrm{E}-\mathrm{S}$ protein spots from $T$. spiralis, which represented only 13 different proteins indicating that there are multiple charge isoforms produced by this species. They observed that the most prominent proteins included the serine protease, the 45$\mathrm{kDa}$ antigen, and the gp43 [36]. In our study, the variable glycosylation is one of the likely reasons explaining the identification of one and the same protein in several horizontally migrating spots (Figure 1A, B). This is supported by previous proteomic studies, which showed that the 5'-nucleotidase of $T$. spiralis contains three potential $\mathrm{N}$-glycosylation sites [45], and that native $\mathrm{p} 49$ 
protein undergoes glycosylation [46-48]. Such modification is also known to affect the $\mathrm{pI}$ and Mw values of the protein [49], thereby explaining the unexpected migration pattern (i.e., increased $\mathrm{p} / \mathrm{Mw}$ values) of the identified p49 antigen variants (spots 24 and 60) in T. britovi (Figure 1A, B, Additional file 1: Table S2). Similarly, previous studies done by Romaris et al. have also demonstrated that $T$. spiralis may express more than one isoform of the protein and that a common precursor protein could undergo variable post-translational processing [50]. Our findings support this as the serinetype proteases were also identified in several protein spots in T. spiralis E-S proteome (Figure 1A, B, Additional file 1: Table S2). Protein modification could also be the reason behind the unsuccessful MS-identification of four protein spots (spots 4, 6, 40, 41) that appear to be specific for $T$. spiralis (Figure 1A, B). No conclusive identification was obtained for these protein spots. The MS/MS spectra after LC-MS/MS analysis of the tryptic peptides derived from these proteins could not be matched with recently released predicted proteins from T. spiralis [31]. Additionally, several proteins specifically produced by $T$. spiralis had low molecular mass for which the LC-MS/MS analysis failed to provide positive identification. In addition, the distinct migration pattern of these proteins (proteins with the same pI but with decreasing molecular weights) is typically observed for T. spiralis E-S proteins (Bien, data not shown), and we suspect that these protein spots could result from posttranslational modification presumably resulting from proteolysis. Proteolysis has been proven to be responsible for post-translational modification of secreted $T$. spiralis E-S protein called MCD-1 (multi-cystatin-like domain protein 1) [51]. MCD-1 belongs to family of cystatins, which exist as high- and low- molecular weight isoforms formed by alternative mRNA splicing, and the resulting proteins are then proteolytically processed to release bioactive peptides [52]. However, there is no evidence of the role of alternative splicing in production of MCD-1 isomers [51]. Instead, the formation of low-molecular weight MCD-1 isomer is suggested to result from proteolytic cleavage of the $\mathrm{C}$-terminal domain III from the secreted protein [51].

Identifications related to proteins showing differential abundance included 10 protein spots from which 5 protein spots (spots $1,33,37,46,52$ ) were more abundant in $T$. britovi and 5 (spots $5,30,31,45,65$ ) were more abundant in the T. spiralis E-S proteome. In T. britovi, these proteins were identified as different glycoproteins (gp43, p49) and serine-protease isoforms as well as a 5'nucleotidase (Additional file 1: Table S2). These proteins were identified also from $T$. spiralis, suggesting that different forms of the same E-S proteins are more produced by this species (Additional file 1: Table S2). Thus, we suggest that both species produce equivalent E-S proteins, which are post-translationally modified to a different extent, which in certain cases seemed to result in species-specific modification. It is tempting to speculate that such differences could contribute to the mechanism by which these two species select the host and establish successful infection.

\section{Immunoproteomic analysis of $T$. spiralis and $T$. britovi E-S proteins}

An immunoproteomic approach was next used to verify which of the identified proteins cross-react with speciesspecific antisera. For this purpose, proteins from E-S extracts of T. spiralis and T. britovi were separated by 2-DE and transferred onto PVDF membrane for treatment with sera from pigs experimentally infected with $T$. spiralis or T. britovi. The experiments, conducted in triplicate, were highly reproducible, yielding similar patterns of immunoreactive proteins (Figure 2B). As shown in Figure 2B, the 2-D immunoblotting of $T$. spiralisand T. britovi E-S proteins with specific antisera results in somewhat different immunoproteomes, including both specifically (spots $5,9,46$, and $31,45,50)$ and commonly (spots $19,37,52)$ recognized antigens. In $T$. britovi, the cross-reactive E-S proteins (10 in total) were found to migrate with pI values around 6 and with molecular weight ranging from 40 to $50 \mathrm{kDa}$. In the case of $T$. spiralis, proteins (10-12 in total) detected with antisera were found to migrate at $40 \mathrm{kDa}$ with slightly higher $\mathrm{pI}$ values than those detected with anti- $T$. britovi antibodies (Figure 2B).

A previous 2-D immunoblotting study by $\mathrm{Wu}$ et al., demonstrated that the E-S products of T. spiralis have mainly three kinds of antigenic proteins composed of 511 isoforms that migrate at about 40-50 kDa [53]. These findings were supported by another study that demonstrated a similar antigenic pattern for the T. spiralis E-S proteins, with three major protein bands migrating between 40-60 kDa that showed high cross-reactivity [54]. In our study, the antigenic proteins had a lower molecular mass, which could be a result of the methods used for proteome analyses and/or individual variations between the antisera used in the present and in the published studies. In the case of $T$. britovi, 2-D immunoblotting revealed two groups of horizontally adjacent antigenic spots (Figure 2B). Previous 1-DE and 2-DE immunoblotting studies involving the crude extract isolated from $T$. britovi and Trichinella genotype $8 \mathrm{ML}$ revealed that the major antigens are acidic with molecular mass values ranging from 45 to $70 \mathrm{kDa}[35,54]$. These highly cross-reactive proteins of $T$. spiralis and $T$. britovi have been identified as glycoproteins with a postulated role in infection and nurse cell development $[55,56]$. Moreover, we suspected that the most 
prominent E-S proteins that were found to react with pig antisera likely corresponded to those found by Robinson and Connolly [36] and could be modified by tyvelose, the dominant and highly immunogenic sugar found in both the TSL-1 antigens and E-S antigens [46]. The tyvelose bearing proteins present in E-S products have been suggested to play a role in establishment and maintenance of the nurse cell, and play a role as mediators in the intestinal phase [57-59]. These proteins may also induce a powerful antibody response in parasitized animals and can be used for immunodiagnostic purposes [60].

In the present study, the specific antibodies against $T$. britovi were found to cross-react with protein spots matching to the location of different 5'-nucleotidase and serine-protease isoforms in the 2-DE-gel (Figure 2A), while the specific antibodies against $T$. spiralis recognized only certain isoforms of the gp43 glycoprotein and serine-proteases. Interestingly, the cell-surface display of the 210-239 amino acid epitope derived from gp43 of $T$. spiralis ML on Salmonella was recently shown to induce a protective immune response against the $T$. spiralis challenge in mice [61]. Proteins specifically recognized by $T$. britovi antisera only included the different 5 'nucleotidase isoforms. Interestingly, one of the protein spots (spot 5), representing one of the 5'-nucleotidase variants, is produced less by $T$. britovi $\mathrm{ML}$ compared to T. spiralis (Figure 3A). This finding suggests that this particular form of the 5 -nucleotidase, which is only recognized by $T$. britovi antisera, is highly antigenic. It is tempting to speculate that differential expression of 5'nucleotidase contributes to immune evasion since it is currently believed that this enzyme is able to regulate host immune and inflammatory responses by modulating nucleotide levels during infection [62].

Interestingly, both antisera also recognized common proteins, such as those identified from spots 19, 37 and 52 (gp43, serine protease/proteinase). This finding indicates that these proteins are more efficiently recognized by the specific antibodies against $T$. spiralis, since according to 2-D DIGE the corresponding protein spots are more abundant in $T$. britovi compared to those detected in $T$. spiralis E-S proteome (Additional file 1: Table S2, Figure 3B). Both of these proteins have been previously shown to be stage-specific ML proteins; the cross-reacting gp43 possess a DNase II-like motif and is suggested to be involved in the formation of nurse cells, while the identified protease is believed to play a crucial role in the development or migration of NBL in host tissues [63]. In addition, proteinase can also serve as an immunodominant antigen, stimulating a protective immune response [64]. Previous studies have demonstrated that $T$. spiralis $\mathrm{ML}$ antigens fall into eight groups according to their recognition by monoclonal and/or polyclonal antibodies. Furthermore, monoclonal antibodies raised against $T$. spiralis and $T$. pseudospiralis also recognize $T$. britovi $[65,66]$. In the present study, the 2DE immunoblotting analyses strengthen these findings by showing that both $T$. spiralis and $T$. britovi antisera recognize a common set of antigens, whereas $T$. britovi antisera also cross-reacted with several isoforms of the 5'-nucleotidase.

\section{Conclusions}

Early clinical diagnosis of trichinellosis is likely to contribute to improved treatment outcomes, however the differentiation of causative species, by serological or biochemical means, has remained proven difficult. In the present study we applied 2-D DIGE and 2-D immunblotting to screen for immune-reactive E-S antigens of diagnostic potential from two important Trichinella species, T. spiralis and T. britovi. In this regard, 17 proteins exhibiting differential expression were identified by LCMS/MS. The identified proteins included 5'-nucleotidase, serine-type proteinase/protease, gp43 and p49 antigens; some of which were suggested to have undergone charged post-translational modification that, in certain cases, seemed to result in species-specific modification of the protein. The antigenic differences of the Trichinella species analyzed by 2-D immunoblotting demonstrated that, in addition to recognizing the same proteins, specific antibodies against $T$. britovi also specifically recognized the different isoforms of the 5'-nucleotidase. To the best of our knowledge, this is the first proteomic study to focus on T. britovi E-S proteins and to show specific immunoreactive proteins among the E$\mathrm{S}$ products of this species.

\section{Additional material}

Additional file 1: Table S2. Identification of T. britovi and T. spiralis E-S proteins showing differential abundance in 2-D DIGE gels. The grey or white backgrounds correspond to proteins that are produced more in $T$. britovi or T. spiralis, respectively.

\section{Abbreviations}

2-DE: Two-dimensional electrophoresis; 2-D DIGE: Two-dimensional difference gel electrophoresis; LC-MS/MS: Liquid chromatography-tandem mass spectrometry; E-S: Excretory-secretory; IEF: Isoelectric focusing; ML: Muscle larvae; DIA: Differential in-gel analysis; BVA: Biological variation analysis; NBL: Newborn larvae; PVDF: Polyvinylidene difluoride.

\section{Acknowledgements}

We thank Professor Antti Sukura for offering the laboratory facilities to our use and commenting the manuscript. We are also grateful Dr A.M. Morales (Department of Infectious, Parasitic and Immunomediated Diseases, Istituto Superiore di Sanita, Rome, Italy) and K. Nöckler (Federal Institute for Risk Assessment, Berlin, Germany) for the gift of the experimentally Trichinellainfected sera. This research was supported by the Polish Ministry of Science and Higher Education grant No, NN303 344935. 


\section{Author details}

'Witold Stefanski Institute of Parasitology of the Polish Academy of Sciences, 51/55 Twarda Street, 00818 Warsaw, Poland. ${ }^{2}$ Department of Veterinary Biosciences, University of Helsinki, P.O. Box 66, 00014 Helsinki, Finland. ${ }^{3}$ Department of Food and Environmental Sciences, University of Helsinki, P.O. Box 66, 00014 Helsinki, Finland. ${ }^{4}$ Institute of Biotechnology, University of Helsinki, P.O. Box 65, 00014 Helsinki, Finland.

\section{Authors' contributions}

$J B, A N, K G$ and KS conceived the study idea, designed it and performed the most of the experiments. JB, KS and AN prepared the first draft of the manuscript. JB and KG prepared the antigen proteins. JB, KS and PV performed the 2-D DIGE experiments and immunoblotting. KS and TAN did mass spectrometric analyses. KS and PV helped with the data analysis and interpretation. BM and WC did the theoretical supervising of the manuscript. All the authors read and approved the final manuscript.

\section{Competing interests}

The authors declare that they have no competing interests.

Received: 21 November 2011 Accepted: 11 February 2012

Published: 11 February 2012

\section{References}

1. Murrell KD, Lichtenfels RJ, Zarlenga DS, Pozio E: The systematics of Trichinella with a key to species. Vet Parasitol 2000, 93:293-307.

2. Pozio E, Zarlenga DS: Recent advances on the taxonomy, systematics and epidemiology of Trichinella. Int J Parasitol 2005, 35:1191-1204.

3. Krivokapich SJ, Prous CL, Gatti GM, Confalonieri V, Molina V, Matarasso H, Guarnera E: Molecular evidence for a novel encapsulated genotype of Trichinella from Patagonia, Argentina. Vet Parasitol 2008, 156:234-240.

4. Nowosad P, Pozio E: First report of Trichinella britovi in wildlife from Poland. Acta Parasitologica 1998, 43:236-237.

5. Cabaj W, Pozio E, Moskwa B, Malczewski A: Trichinella britovi and T. spiralis in red foxes (Vulpes vulpes) in Poland. Acta Parasitologica 2000, 45:340-344.

6. Pozio E: Trichinellosis in the European Union: epidemiology, ecology and economic impact. Parasitol Today 1998, 14:35-38.

7. Dupouy-Camet J: Trichinellosis: a worldwide zoonosis. Vet Parasitol 2000, 93:191-200.

8. Carnieri I, Ancelle T, Dupouy-Camet J, Pozio E: Different aetiological agents cause the European outbreaks of horsemeat induced human trichinellosis. In Trichinellosis. Edited by: Tanner CE, Martinez-Fernandez AR, Bolas-Fernandez F. Madrid: Consejo Superior de Investigaciones Cientificas, Spain Publishing; 1998:387-391.

9. Ainsworth R, Andrew JRL, Abernethy D: Trichinella pseudospiralis the first human case. In Trichinellosis. Edited by: Cambell W, Pozio E, Bruschi F. Rome: Istituto Superiore di Saitá, Italia Publishing; 1994:461-465.

10. Gomez-Garcia V, Hernandez-Quero J, Rodrguez-Osorio M: Short report: Human infection with Trichinella britovi in Granada, Spain. Am J Trop Med Hyg 2003, 68:463-464.

11. Gari-Toussaint M, Tieulié N, Baldin JL, Dupouy-Camet J, Delaunay $P$, Fuzibet JG, Le Fichoux Y, Pozio E, Marty P: Human trichinellosis due to Trichinella britovi in southern France after consumption of frozen wild boar meat. Eurosurveillance 2005, 10:550.

12. Boireau P, Vallee I, Roman T, Perret C, Mingyuan L, Gamble HR, Gajadhar A: Trichinella in horses: a low frequency infection with high human risk. Vet Parasitol 2000, 93:309-320.

13. Pozio E, Serrano FJ, La Rosa G, Reina D, Perez-Martin E, Navarrete I: Evidence of potential gene flow in Trichinella spiralis and in Trichinella britovi in nature. J Parasitol 1997, 83:163-166.

14. Kapel CM, Oivanen L, La Rosa G, Mikkonen T, Pozio E: Evaluation of two PCR-based techniques for molecular epidemiology in Finland, a highendemic area with four sympatric Trichinella species. Parasite 2001, 8:39-43.

15. Cabaj W, Moskwa B, Pastusiak K, Bień J: Distribution of Trichinella species in Poland. Kosm Probl Nauk Biologicznych 2005, 54:95-103.

16. Rodríguez E, Olmedo J, Ubeira FM, Blanco C, Gárate T: Mixed infection, Trichinella spiralis and Trichinella britovi, in a wild boar hunted in the Province of Cáceres (Spain). Exp Parasitol 2008, 119:430-432.
17. Liciardi M, Marucci G, Addis G, Ludovisi A, Gomez Morales MA, Deiana B, Cabaj W, Pozio E: Trichinella britovi and Trichinella spiralis mixed infection in a horse from Poland. Vet Parasitol 2009, 161:345-348.

18. Cabaj W, Moskwa B, Pastusiak K, Malczewski A: Trichinellosis in wild animals and domestic pigs in Poland. Med Weter 2004, 60:80-83.

19. Despommier DD: Biology. In Trichinella and trichinosis. Edited by: Campbell WC. New York: Plenum Press; 1983:75-151.

20. Mitreva M, Jasmer DP: Biology and genome of Trichinella spiralis. WormBook 2006, 23:1-21.

21. Bruschi F, Murrell KD: New aspects of human trichinellosis: the impact of new Trichinella species. Postgrad Med J 2002, 78:15-22.

22. Pozio E, Varese P, Morales MA, Croppo GP, Pelliccia D, Bruschi F: Comparison of human trichinellosis caused by Trichinella spiralis and by Trichinella britovi. Am J Trop Med Hyg 1993, 48:568-575.

23. Dupouy-Camet J, Paugam A, De Pinieux G, Lavarde V, Vieillefond A: Trichinella murrelli: pathological features in human muscles at different delays after infection. Parasite 2001, 8:S176-S179.

24. Jongwutiwes S, Chantachum N, Kraivichian P. Siriyasatien P. Putaporntip C, Tamburrini A, La Rosa G, Sreesunpasirikul C, Yingyourd P, Pozio E: First outbreak of human trichinellosis caused by Trichinella pseudospiralis. Clin Infect Dis 1998, 26:111-115

25. Ranque S, Faugère B, Pozio E, La Rosa G, Tamburrini A, Pellissier JF, Brouqui P: Trichinella pseudospiralis outbreak in France. Emerg Infect Dis 2000, 6:543-547.

26. Gamble HR, Anderson WR, Graham CE, Murrel KD: Diagnosis of swine trichinosis by enzyme-linked immunosorbent assay (ELISA) using an excretory-secretory antigen. Vet Parasitol 1983, 13:349-361.

27. Su X, Prestwood AK, McGraw RA: Cloning and expression of complementary DNA encoding an antigen of Trichinella spiralis. Mol Biochem Parasitol 1991, 77:76-82.

28. Sofronic-Milosavljevic L, Pozio E, Patrascu IV, Skerovic N, Gomez Morales MA, Gamble HR: Immunodiagnosis of Trichinella infection in the horse. Parasite 2001, 8:260-262.

29. Yera H, Andiva S, Perret C, Limonne D, Boireau P, Dupouy-Camet J. Development and evaluation of a Western blot kit for diagnosis of human trichinellosis. Clin Diagn Lab Immunol 2003, 10:793-796.

30. Gamble HR, Pozio E, Bruschi F, Nöckler K, Kapel CM, Gajadhar AA: International Commission on Trichinellosis: recommendations on the use of serological tests for the detection of Trichinella infection in animals and man. Parasite 2004, 11:3-13.

31. Mitreva M, Jasmer DP, Zarlenga DS, Wang Z, Abubucker S, Martin J, Taylor CM, Yin Y, Fulton L, Minx P, et al: The draft genome of the parasitic nematode Trichinella spiralis. Nat Genet 2011, 43:228-235.

32. Lilley KS, Razzaq A, Dupree P: Two-dimensional gel electrophoresis: recent advances in sample preparation, detection and quantitation. Curr Opin Chem Biol 2002, 6:46-50.

33. Westermeier R, Marouga R: Protein detection methods in proteomics research. Biosci Rep 2005, 25:19-32

34. Viswanathan S, Unlü M, Minden JS: Two-dimensional difference gel electrophoresis. Nat Protoc 2006, 1:1351-1358.

35. Dea-Ayuela MA, Bolas-Fernandez F: Two-dimensional electrophoresis and mass spectrometry for the identification of species-specific Trichinella antigens. Vet Parasitol 2005, 132:43-49.

36. Robinson MW, Connolly B: Proteomic analysis of the excretory-secretory proteins of the Trichinella spiralis L1 larva, a nematode parasite of skeletal muscle. Proteomics 2005, 5:4525-4532.

37. Robinson MW, Gare DC, Connolly B: Profiling excretory-secretory proteins of Trichinella spiralis muscle larvae by two dimensional gel electrophoresis and mass spectrometry. Vet Parasitol 2005, 132:37-41.

38. Näreaho A, Ravanko K, Hölttä E, Sukura A: Comparative analysis of Trichinella spiralis and Trichinella nativa proteins by two-dimensional gel electrophoresis. Parasitol Res 2006, 98:349-354

39. Robinson MW, Greig R, Beattie KA, Lamont DJ, Connolly B: Comparative analysis of the excretory-secretory proteome of the muscle larva of Trichinella pseudospiralis and Trichinella spiralis. Int J Parasitol 2007, 37:139-148.

40. Cabaj W, Przyjałkowski Z: Biological characteristics of Trichinella spiralis and T. pseudospiralis infections in mice. Acta Parasitologica Polonica 1987, 32:195-204.

41. Gamble HR, Bessonov AS, Cuperlovic K, Gajadhar AA, van Knapen F, Nöeckler K, Schenone H, Zhu X: International Commission on 
Trichinellosis: recommendations on methods for the control of Trichinella in domestic and wild animals intended for human consumption. Vet Parasitol 2000, 93:393-408.

42. O'Connell KL, Stultus JT: Identification of mouse liver proteins on twodimensional electrophoresis gels by matrix-assisted laser desorption/ ionization mass spectrometry of in situ enzymatic digests. Electrophoresis 1997, 18:349-359.

43. Shevchenko A, Wilm M, Vorm O, Mann M: Mass spectrometric sequencing of proteins silver-stained polyacrylamide gels. Analitical Chem 1996, 68:850-858.

44. Koskenniemi K, Koponen J, Kankainen M, Savijoki K, Tynkkynen S, de Vos WM, Kalkkinen N, Varmanen P: Proteome analysis of Lactobacillus rhamnosus GG using 2-D DIGE and mass spectrometry shows differential protein production in laboratory and industrial-type growth media. $J$ Proteome Res 2009, 8:4993-5007.

45. Gounaris K, Selkirk ME, Sadeghi SJ: A nucleotidase with unique catalytic properties is secreted by Trichinella spiralis. Mol Biochem Parasitol 2004, 136:257-264.

46. Wisnewski N, MCNeil M, Grieve RB, Wassom DL: Characterization of novel fucosyl- and tyvelosyl-containing glycoconjugates from Trichinella spiralis muscle stage larvae. Mol Biochem Parasitol 1993, 61:25-35.

47. Yan $Y$, Tong GZ, Lu JL: Cloning of two structural genes encoding specific proteins in ES antigen from Trichinella spiralis muscle larvae and their high level expression in E. coli and yeast. Chin J of Vet Sci 1997, 17:581-588.

48. Denkers EY, Wassom DL, Hayes CE: Characterization of Trichinella spiralis antigens sharing an immunodominant, carbohydrate-associated determinant distinct from phosphorylcholine. Mol Biochem Parasitol 1990, 41:241-249.

49. Baek WO, Vijayalakshmi MA: Effect of chemical glycosylation of RNase A on the protein stability and surface histidines accessibility in immobilized metal ion affinity electrophoresis (IMAGE) system. Biochim Biophys Acta 1997, 1336:394-402.

50. Romaris F, North SJ, Gagliardo LF, Butcher BA, Ghosh K, Beiting DP, Panico M, Arasu P, Dell A, Morris HR, Appleton JA: A putative serine protease among excretory-secretory glycoproteins of L1 Trichinella spiralis. Mol Biochem Parasitol 2002, 122:149-160.

51. Robinson MW, Massie DH, Connolly B: Secretion and processing of a novel multi-domain cystatin-like protein by intracellular stages of Trichinella spiralis. Mol Biochem Parasitol 2007, 151:9-17.

52. Dubin G: Proteinaceous cystein protease inhibitors. Cell Mol Life Sci 2005 62:653-669.

53. Wu Z, Nagano I, Takahashi Y: A panel of antigens of muscle larvae of Trichinella spiralis and T. pseudospiralis as revealed by two-dimensional Western blot and immunoelectron microscopy. Parasitology 1999, 118:615-622.

54. Dea-Ayuela MA, Bolase-Fernandez F: Dynamics of the lgG3 responses following immunisation of BALB/C mice with somatic and excretory/ secretory antigens from various Trichinella species. Folia Parasitol (Praha) 2000, 47:172-180.

55. Mcvay CS, Tsung A, Appleton J: Participation of parasite surface glycoproteins in antibody-mediated protection of epithelial cells against Trichinella spiralis. Infect Immun 1998, 66:1941-1945.

56. Vassilatis DK, Polvere RI, Despommier DD, Goold AM, Van der Ploeg LH: Developmental expression of a 43-kDa secreted glycoprotein from Trichinella spiralis. Mol Biochem Parasitol 1996, 78:13-23.

57. Appleton JA, Schain LR, McGregor DD: Rapid expulsion of Trichinella spiralis in suckling rats: mediation by monoclonal antibodies. Immunology 1988, 65:487-492.

58. Yao C, Jasmer DP: Nuclear antigens in Trichinella spiralis infected muscle cells: nuclear extraction, compartmentalization, and complex formation. Mol Biochem Parasitol 1998, 92:207-218.

59. McVay CS, Bracken P, Gagliardo LF, Appleton J: Antibodies to tyvelose exhibit multiple modes of interference with the epithelial niche of Trichinella spiralis. Infect Immun 2000, 68:1912-1918.

60. Appleton JA, Bell RGM, Homan W, van Knapen F: Consensus on Trichinella spiralis antigens and antibody. Parasitol Today 1991, 7:190-192.

61. Pompa-Mera EN, Yepez-Mulia L, Ocana-Mondragon A, Garcia-Zepeda EA Ortega-Pierres G, Gonzalez-Bonilla CR: Trichinella spiralis: Intranasal immunization with attenuated Salmonella enterica a gp43 antigen- derived 30mer epitope elicits protection in BALB/c mice. Exp Parasitol 2011, 129:393-401

62. Gounaris K: Nucleotidase cascades are catalyzed by secreted proteins of the parasitic nematode Trichinella spiralis. Infect Immun 2002, 70:4917-4924.

63. Liu MY, Wang XL, Fu BQ, Li CY, Wu XP, Rhun D, Chen XJ, Boireau P: Identification of stage-specifically expressed genes of Trichinella spiralis by suppression subtractive hybridization. Parasitology 2007, 135:77-83.

64. Todorova VK, Stoyanov DI: Partial characterization of serine proteinases secreted by adult Trichinella spiralis. Parasitol Res 2000, 86:684-687.

65. Bioreau P, Vayssier M, Fabien JF, Perret C, Calamel M, Soulé C: Characterization of eleven antigenic groups in Trichinella genus and identification of stage and species markers. Parasitology 1997, 115:641-651.

66. Ortega-Pierres MG, Yepez-Mulia L, Homan W, Gamble HR, Lim PL, Takahashi Y, Wassom DI, Appleton JA: Workshop on a detailed characterization of Trichinella spiralis antigens: a platform for future studies on antigens and antibodies to this parasite. Parasite Immunol 1996, 18:273-284.

doi:10.1186/1477-5956-10-10

Cite this article as: Bien et al: Comparative analysis of excretorysecretory antigens of Trichinella spiralis and Trichinella britovi muscle larvae by two-dimensional difference gel electrophoresis and immunoblotting. Proteome Science 2012 10:10.

\section{Submit your next manuscript to BioMed Central and take full advantage of:}

- Convenient online submission

- Thorough peer review

- No space constraints or color figure charges

- Immediate publication on acceptance

- Inclusion in PubMed, CAS, Scopus and Google Scholar

- Research which is freely available for redistribution

Submit your manuscript at www.biomedcentral.com/submit
Ciomed Central 